DOI: https://doi.org/10.47405/mjssh.v6i6.826

\begin{tabular}{|c|c|}
\hline The & Malaysian Journal of Social Sciences and Humanities (MJSSH) \\
\hline Malaysian Journal of & Volume 6, Issue 6, June 2021 \\
\hline 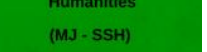 & e-ISSN : 2504-8562 \\
\hline & $\begin{array}{l}\text { Journal home page: } \\
\text { www.msocialsciences.com }\end{array}$ \\
\hline
\end{tabular}

\title{
Kepuasan Atlet Bola Tampar: Hubungannya dengan Pengurusan Risiko di Institusi Pengajian Tinggi di Malaysia
}

\author{
Muhamad Suhaimi Taat ${ }^{1}$, Ahmad Fadly Abdul Rahman', Hasnol Nordin', Nazmizan Muhammad² \\ ${ }^{1}$ Fakulti Psikologi dan Pendidikan, Universiti Malaysia Sabah (UMS) \\ ${ }^{2}$ Fakulti Sains Gunaan dan Kemanusiaan, Universiti Malaysia Perlis (UniMAP)
}

Correspondence: Muhamad Suhaimi Taat (suhaimi@ums.edu.my)

\begin{abstract}
Abstrak
Kajian ini bertujuan untuk mengenal pasti hubungan pengurusan risiko dengan kepuasan atlet bola tampar di institusi penggajian tinggi di Malaysia. Seramai 240 orang atlet yang terdiri daripada atlet bola tampar di 20 buah universiti awam di Malaysia sebagai responden. Kajian ini ialah satu kajian kuantitatif yang menggunakan kaedah tinjauan. Adaptasi soal selidik telah digunakan dalam kajian ini berdasarkan Athlete Satisfaction Questionnaire (ASQ) (Reimer \& Chelladurai, 1998) \& Asiah Pilus (2009) dan Pengurusan Risiko (Fatimah Mustaffa (2015) dan Jaffry Zakaria (2015). Kajian rintis dijalankan untuk menguji kesahan dan kebolehpercayaan instrumen kajian. Analisa data kajian menggunakan program SPSS versi 24.0 (Statiscal Package for Social Science). Analisis statistik diskriptif dan inferensi digunakan untuk menguji hipotesis kajian. Dapatan kajian menunjukkan terdapat hubungan yang signifikan diantara pengurusan risiko dengan kepuasan atlet. Aspek pengetahuan jurulatih menunjukkan hubungan kuat dengan kepuasan atlet. Aspek aktiviti semasa latihan menunjukkan hubungan yang rendah terhadap kepuasan atlet. Kajian ini mencadangkan pengurusan risiko dalam latihan dan pertandingan terhadap atlet universiti boleh disesuaikan dengan keperluan semasa seperti kecekapan kakitangan sukan dan jurulatih. Kakitangan sukan dan jurulatih perlu berinovatif dan mempunyai ilmu yang baik dalam mengendalikan pengurusan risiko agar keselamatan dan prestasi atlet berada di tahap yang baik. Justeru itu, atlet lebih yakin dengan persekitaran latihan dan pertandingan yang selamat bagi mencapai tahap kepuasan yang maksima dan meningkatkan prestasi atlet. Selain itu, penyediaan pengurusan risiko yang baik dan selamat dapat mendorong atlet atau pelajar bergiat aktif dalam aktiviti sukan di peringkat kampus hingga mewakili universiti ke peringkat yang lebih tinggi dan menjaga kualiti hidup yang normal dan harmoni.
\end{abstract}

Kata kunci: pengurusan, risiko, kepuasan, universiti, atlet

\section{Volleyball Athlete Satisfaction: Its Relationship with Risk Management in Institutions of Higher Learning in Malaysia}

\begin{abstract}
This study aims to identify risk management relationships with athlete satisfaction at institute of higher learning in Malaysia. A total of 240 athletes comprising volleyball athletes at 20 public universities in Malaysia as respondents. This study is a quantitative study using survey methods. Questionnaire adaptation was used in this study based on Athlete Satisfaction Questionnaire (ASQ) (Reimer \& Chelladurai, 1998), Asiah Pilus (2009) and Risk Management (Fatimah Mustaffa (2015) and Jaffry Zakaria (2015). Pilot studies are carried out to test the traceability and reliability of the
\end{abstract}


instruments of the study. Analysis of the study data using the SPSS program version 24.0 (Statistical Package for Social Science). Analysis of descriptive statistics and inferences are used to test the study hypothesis. The findings showed that there is a significant relationship between risk management and athlete satisfaction. The aspect of coach knowledge shows strong relationships with athlete satisfaction. The current aspect of activity of training shows a low link to athlete satisfaction. The study recommended that risk management in training and competition against university athletes can be tailored to current needs such as the efficiency of sports personnel and coaches. Sports staff and coaches need to be innovative and have good knowledge in handling risk management so that athletes' safety and performance are at a good level. Hence, athletes are more confident in the training environment and safe competition to achieve maximum satisfaction and improve athletes' performance. In addition, providing good and safe risk management can encourage athletes or students to be actively involved in sports activities at the campus level to represent the university to a higher level and maintain a normal and harmonious quality of life.

Keywords: management, risks, satisfaction, university, athlete

\section{Pengenalan}

Selaras dengan Dasar Pembangunan sukan Institusi Pengajian Tinggi (DPSIPT) iaitu melahirkan keupayaan atlet menggunakan ilmu pengetahuan yang diperolehi semasa di universiti untuk membantu meningkatkan pencapaian sukan. Bagi melahirkan atlet yang berkualiti dan berprestasi tinggi dalam arena sukan, faktor-faktor keselamatan atau pengurusan risiko dalam latihan atau pertandingan perlu fikirkan bagi menjamin kestabilan dalam kualiti hidup dan prestasi pada seseorang atlet. Pengurusan risiko adalah satu pengurusan atau tatacara kerja sesebuah organisasi sukan bagi memastikan persekitaran atau tempat seperti seperti tempat latihan, peralatan dan aktiviti atau program agar selamat atau menghindar daripada kemalangan atau kecederaan. Fatimah Mustaffa (2015) menyatakan pengurusan risiko penting dalam industri sukan bagi menyediakan dan memastikan persekitaran selamat untuk setiap program sukan. Pengurusan risiko sukan bertujuan bagi mengawal, mengelak dan meminimakan risiko kemalangan dan kecederaan.

Persekitaran latihan atau pertandingan yang baik serta selamat perlu titik beratkan oleh pengurusan pasukan atau jurulatih bagi menjamin dari kemalangan yang merbahayakan atlet. Fasiliti sukan di universiti adalah penting dalam menggalakkan atlet aktif dalam aktiviti fizikal dan latihan hari bagi persediaan menghadapi pertandingan. Forrester (2014) telah menjalankan kajian tinjauan ke atas 38 buah kolej dan universiti di seluruh Amerika Syarikat. Seramai 33,500 pelajar terlibat dalam kajian ini. Hasil kajian menunjukkan bahawa hampir $90 \%$ pelajar dalam kalangan atlet menyatakan mereka menghabiskan sekurang-kurangnya 30 minit setiap kali menggunakan fasiliti sukan di kampus.

Selain daripada penyediaan persekitaran latihan yang baik dan selamat, faktor kepuasan harus di tekankan oleh sesebuah universiti. Kepuasan atlet di institusi pengajian tinggi adalah sesuatu isu yang semakin popular dibincangkan serta dikaji bagi mendapatkan jawapan yang lebih tepat serta memberi faedah kepada sesebuah organisasi sukan, pasukan atau individu (Asiah \& Rosli, 2009; Anuar, 2010). Kepuasan atlet terhadap pengurusan risiko adalah sesuatu yang amat penting bagi seseorang atlet bagi mencapai kejayaan dan meningkatkan prestasi. Kepuasan atlet dalam latihan atau kejohanan yang disertainya bukan sahaja dipengaruhi oleh faktor diri atlet sendiri bahkan terdapat faktor lain seperti ergonomik latihan atau pengurusan risiko bagi mengelak daripada mengalami kecederaan semasa latihan dan pertandingan (Jaffry et al., 2015; Fatimah, 2015).

Oleh itu, kajian ini amat bertepatan bagi mengenal pasti pengurusan risiko terhadap atlet di universiti awam Malaysia. Penekanan terhadap aspek-aspek dalam pengurusan risiko akan dapat mengenal pasti hubungan dan pengaruh terhadap kepuasan atlet bagi penambahbaikan sistem pengurusan risiko di organisasi sukan khasnya di universiti. Selain itu, ia dapat menjadi sumber rujukan kepada setiap pengurusan sukan di universiti, sekolah, kelab, jabatan kerajaan, swasta serta persatuan negeri dan kebangsaan sebagai panduan dalam pengurusan risiko sukan. Ini memberi impak yang baik kepada pengurusan sukan di universiti sebagai satu badan pengurusan sukan yang dijadikan panduan kepada 
setiap organisasi sukan lain bagi menjamin kualiti kehidupan atlet dan meningkatkan prestasi latihan dari masa ke semasa.

\section{Pernyataan Masalah}

Kepuasan atlet di institutsi pendidikan adalah sesuatu isu yang semakin popular dibincangkan serta dikaji bagi mendapatkan jawapan yang lebih tepat serta memberi faedah kepada sesebuah organisasi sukan, pasukan atau individu (Asiah \& Rosli, 2009; Anuar, 2010). Kepuasan seseorang atlet adalah satu psikologi dan keadaan emosi yang menunjukkan sesuatu hasil yang diperoleh (Crompton, 2000; Cole, 2006). Pencapaian prestasi seseorang atlet bergantung kepada motivasi (Mohamad Nizam et al., 2017) yang memberikan kepuasan kepada atlet terhadap apa yang mereka rasai dalam sesuatu pertandingan atau latihan.

Kepuasan atlet terhadap pengurusan risiko adalah sesuatu yang amat penting bagi seseorang atlet mencapai kejayaan. Kepuasan atlet dalam latihan atau pertandingan yang disertainya bukan sahaja dipengaruhi oleh faktor diri atlet sendiri akan tetapi juga oleh sebab faktor-faktor lain. Contohnya pada tahun 2001, pasukan bola tampar lelaki Malaysia mendapat pingat perak, Datuk Lee Chong Wei dan kecemerlangan Datuk Nicol Ann David yang pernah memegang status pemain nombor satu dunia acara badminton dan skuasy banyak dipengaruhi oleh faktor kesungguhan pemain itu sendiri, dorongan dan motivasi dari pakar psikologi sukan (Duda \& Nicholls, 2006; Shahruddin, 2005), pengurusan program latihan yang dirangka oleh jurulatih semasa latihan sama ada offside competition dan onsite competition (Chelladurai, 1984) serta kepentingan pengurusan risiko dalam sukan bagi mengelak daripada kecederaan semasa latihan dan pertandingan (Jaffry et al., 2015; Fatimah, 2015).

Oleh itu, dalam melatih atlet bagi persediaan menghadapi pertandingan, faktor kepuasan atlet adalah sesuatu perkara yang penting dan perlu diperhalusi bagi meningkatkan prestasi seseorang atlet dengan kualiti latihan yang diberikan dan dijadualkan. Selain itu, untuk memberi keselesaan dan kepuasan dalam menjalani latihan, organisasi sukan di universiti seharusnya menitik beratkan faktor-faktor keselamatan atau pengurusan risiko yang boleh mendatangkan kecederaan kepada atlet. Berdasarkan pada tinjauan dan statistik yang diperoleh menunjukkan berlaku peningkatan dalam jumlah kemalangan yang berlaku dalam semua industri termasuk industri sukan. Bermula dari tahun 2008 sehinggalah tahun 2012 peningkatan jumlah kemalangan secara mendadak berlaku dan dilaporkan dalam laporan tahunan yang dikeluarkan. Pada tahun 2008 jumlah kemalangan melaporkan sebanyak 54, 133 kemalangan, tahun 2009 melaporkan sebanyak 55, 186 kemalangan, tahun 2010 melaporkan sebanyak 57, 639 kemalangan, 2011 sebanyak 59, 897 kemalangan dan 2012 sebanyak 61, 552 kemalangan dilaporkan (Jabatan Perangkaan Malaysia, 2011).

Tambahan pula, senario di Malaysia, masalah berkaitan amalan pengurusan risiko telah menjadi satu kebimbangan dan kes berkaitan kecederaan semakin mendapat liputan pihak media. Menurut Tie (2002), langkah mengambil tindakan mahkamah ke atas pihak pengurusan atau jurulatih ialah suatu unsur yang sudah meresap ke dalam bidang sukan di pendidikan Malaysia. Oleh sebab tiada perancangan pengurusan risiko, ibu bapa atau pelajar sering mendakwa guru, staf sukan dan jurulatih di mahkamah atas kecuaian dan kegagalan mereka dalam melaksanakan langkah berjaga-jaga. Antara contoh kes kegagalan penyeliaan ialah kecuaian dalam mengambil langkah efektif menyebabkan pelajar bawah seliaannya buta mata kiri ketika bermain hoki (Malaysia, 2010) dan pelajar mati lemas semasa mengikuti program aktiviti luar (Malaysia, 2011). Kes seterusnya ialah akibat kecuaian jurulatih memeriksa ikatan tali semasa aktiviti abseling, yang menyebabkan seorang atlet patah tulang tapak kaki (IPGKPM, 2011).

Dapat dilihat khabar berita berkaitan pelajar atau atlet kemalangan ketika menjalani latihan atau aktiviti sukan, hal ini amat merbahaya kepada atlet lebih lagi atlet yang daripada kalangan pelajar. Asha Hasnimy dan Mat Azmin (2011), semasa seseorang atlet berlatih atau bertanding mempunyai implikasi kecederaan yang ketara ke atas badan bukan sahaja boleh membahayakan keselamatan malah boleh mendatangkan maut kepada atlet tersebut. Memandangkan kekerapan kemalangan yang tinggi dalam industri sukan ia telah menimbulkan pelbagai komplikasi yang negatif. Komplikasi yang 
negatif ini adalah kebimbangan penjaga dan ibu bapa untuk membenarkan anak-anak mereka terlibat dalam aktiviti sukan kerana dikhuatiri akan mendatangkan risiko kecederaan (Mawarni, Lee, Zarina \& Rosli, 2006). Oleh itu, pihak pentadbiran sukan di universiti seperti Pusat Sukan serta jurulatih seharusnya peka terhadap keselamatan dan mementingkan faktor-faktor yang boleh mendatangkan risiko serta kecederaan terhadap atlet di bawah jagaan mereka demi kejayaan yang berharga terhadap diri atlet dan universiti.

Oleh itu, kajian berkaitan pengurusan risiko terhadap kepuasan atlet di universiti perlu dijalankan bagi mengenal pasti kebaikan dan kelemahan yang terdapat dalam pengurusan atlet khasnya di universiti Malaysia. Ini adalah bagi meningkatkan mutu kualiti pengurusan sukan di semua universiti di Malaysia agar mencapai matlamat KPT yang ingin melahirkan atlet di kalangan pelajar yang bertaraf dunia sekali gus dapat mengharumkan IPT Malaysia di peringkat dunia.

\section{Objektif Kajian}
i. Mengenal pasti kekerapan latihan atlet.
ii. Mengenal pasti peringkat tertinggi penglibatan atlet.
iii. Menganalisis hubungan pengurusan risiko dengan kepuasan atlet.

\section{Sorotan Literatur}

Berdasarkan dapatan kajian berkaitan pengurusan risiko yang dijalankan oleh Fagher et.al., (2016) melaporkan prosedur kesihatan boleh mencegah kecederaan atlet. Walau bagaimanapun, terdapat juga hasil kajian yang menunjukkan dapatan yang berbeza, misalnya kajian oleh Asha Hasnimy dan Mat Azmin (2011) serta Vince dan Emma (2014) menjelaskan berkaitan kecederaan anggota badan altet dalam latihan serta semasa pertandingan. Kajian oleh Chunderpal dan Jhalukpreya (2010) berkenaan Risk Manangment Practices of High School Sport Coaches and Administrators. Kajian tersebut untuk mengenal pasti dimensi keselamatan utama sukan sekolah. Kajian mereka juga untuk menilai amalan pengurusan risiko yang dilaksanakan oleh jurulatih dan pentadbir di sekolah tinggi. Dapatan kajian mendapati kesedaran jurulatih dan pentadbir yang berkaitan mengenai tugas perundangan risiko. Dapatan juga menunjukkan faktor keselamatan individu tidak ditangani secukupnya dan keperluan minimum asas tertentu tidak dipenuhi. Penemuan ini mencadangkan garis panduan disediakan untuk membolehkan jurulatih dan pendidik menguruskan risiko yang berpotensi berlaku kepada pelajar. Ini agar atlet dan pelajar mengalami persekitaran yang baik serta tidak mengancam keselamatan mereka hasil daripada aktiviti sukan.

Manakala Fatemeh et al., (2012) dalam kajian An Evaluation of Sports Safety in Public Universities of Golestan Province of Iran. Kajian ini adalah bertujuan untuk menyiasat keselamatan sukan di universiti awam Golestan, Iran. Kaedah penyelidikan yang digunakan adalah deskriptif. Kemudahan sukan yang terlibat merangkumi semua kemudahan sukan di universiti awam yang terletak di wilayah Golestan. Senarai semak pemeriksaan keselamatan yang digunakan untuk mana-mana kebolehpercayaan dengan ujian Alpha Cronbach $(\alpha=0.83)$. Data dikumpulkan dan dianalisis dengan kaedah statistik deskriptif. Hasil kajian menunjukkan bahawa kemudahan sukan di universiti awam Golestan terdiri daripada enam dewan sukan dalam bangunan. Keselamatan dalam kemudahan sukan dan bangunan mencapai masing-masing mencapai skor min 109.08 dan 213.63. Selanjutnya, keputusan yang diperoleh untuk keselamatan kemudahan sukan dan peralatan sukan menunjukkan status sederhana dengan skor min 179.45. Dapatan kajian Chunderpal dan Jhalukpreya (2010), dan Fatemeh et al., (2012) memberi pendekatan yang baik dalam kajian yang melibatkan faktor-faktor yang mempengaruhi kecederaan kepada atlet. Kemudahan sukan yang disediakan adalah penting mempunyai pelan pengurusan risiko agar kecederaan atau kemalangan dapat di kurang semasa latihan dijalankan dan pengetahuan seseorang kakitangan atau jurulatih adalah penanda yang penting bagi mengawal keselamatan dan kecederaan yang boleh berlaku kepada atlet. 
Lachlan et al. (2014) dalam kajian Injury Risk Managemant Plan for Volleyball terhadap atlet bola tampar yang mendapati risiko yang wujud. Artikel ini memberikan pendekatan yang praktikal kepada pengurusan kecederaan dalam sukan bola tampar dan pengurusan pasukan. Dapatan kajian menyatakan bahawa kecederaan utama dalam sukan bola tampar adalah seperti (i) pergelangan kaki terseliuh, (ii) bahu, (iii) patella (lutut), dan (iv) anterior ligamen cruciate.

Kajian oleh Fagher et al., (2016), melaporkan kajian mengenai pengurusan kecederaan dan kesedaran atlet mencegah kecederaan kurang. Beliau mengkaji persepsi atlet terhadap pengalaman kecederaan atlet, faktor risiko dan pencegahan kecederaan. Hasil dapatan kajian beliau bahawa prosedur kesihatan, sukan dan keselamatan atlet perlu ada dan program pencegahan. Penemuan hasil kajian ini selaras Kementerian Pendidikan Malaysia (KPM) telah mengambil langkah yang baik dan proaktif bagi mencegah kemalangan di sekolah mahu pun universiti sejak 1967 dengan mewujudkan Rancangan Kesihatan (KPM 2012; 2002). Antara matlamat polisi yang diwujudkan adalah untuk meningkatkan kefahaman dan penghayatan bahawa pengurusan risiko dan keselamatan hendaklah dijadikan agenda dalam semua aspek pendidikan di Malaysia. Tuntutan terhadap keperluan keselamatan risiko ini menyebabkan organisasi melakukan pelbagai perkara untuk menjamin tahap dan standard keselamatan. Ini dijelaskan oleh penemuan kajian oleh Jaffry (2015) dan Fatimah (2015) terdapat pelbagai faktor mempengaruhi kemalangan dalam amalan pengurusan sukan dan rekreasi.

Kajian oleh Jaffry (2015) mengkaji amalan pengurusan risiko terhadap pengurusan kemudahan Kompleks Jabatan Belia dan Sukan Negeri dan Kompleks Rakan Muda di Malaysia. Kajian berbentuk kuantitatif dan menggunakan soal selidik sebagai instrumen kajian. Sebanyak 255 set borang soal selidik diedarkan kepada responden daripada kakitangan Kompleks Rakan Muda dan Kompleks JBS di Malaysia. Bilangan lelaki lebih ramai daripada bilangan wanita dalam menjawab soalan dan menjadi subjek kajian. Lapan aspek merupakan faktor elemen utama dalam menilai tahap amalan pengurusan risiko kemudahan iaitu proses pemeriksaan, prosedur penyelenggaraan, kakitangan pengurusan, pelan kecemasan, reka bentuk kemudahan, pengurusan program, maklumat pengguna dan polisi insurans. Dapatan kajian mendapat terdapat perbezaan yang signifikan dari aspek amalan pengurusan risiko pelan kecemasan. Dapatan kajian juga menunjukkan pelan kecemasan dan reka bentuk kemudahan merupakan faktor yang menyumbang besar terhadap amalan pengurusan risiko kemudahan. Kajian juga menunjukkan bahawa kompleks JBS negeri menunjukkan interpretasi tahap penarafan yang tinggi untuk proses pemeriksaan, prosedur penyelenggaraan, reka bentuk kemudahan, pengurusan program dan maklumat pengguna. Walau bagaimanapun kompleks rakan muda pula menunjukkan interpretasi tahap penarafan yang sederhana untuk kakitangan pengurusan, pelan kecemasan, pengurusan program, maklumat pengguna dan polisi insurans. Selain itu pengkaji telah menyatakan bahawa faktor-faktor yang boleh menyebabkan kemalangan dan perlu diambil berat dalam aktiviti sukan adalah tempat atau kawasan, pengetahuan kakitangan, peralatan, rekod kesihatan pengguna dan program atau aktiviti yang dilakukan.

Manakala kajian oleh Fatimah (2015) pula mengenai konstruk amalan pengurusan risiko sukan iaitu Amalan Pengurusan Risiko Sukan (APRS) dalam jurulatih sukan Institut Pendidikan Guru Malaysia. Kajian bentuk kuantitatif dan menggunakan soal selidik sebagai instrumen kajian. Kajian ini bertujuan untuk mengenal pasti dan membentuk konstruk APRS jurulatih IPG bagi menghasilkan kerangka APRS. Kajian beliau berkaitan pengaruh faktor kompetensi dalam terhadap APRS yang dilaksanakan oleh jurulatih sukan. Kajian ini juga untuk menguji dan mengesahkan secara empirikal model APRS. Kajian ini melibatkan sampel seramai 39 jurulatih dan 120 atlet dari Institut Pendidikan Guru seluruh Malaysia. Kesemua konstruk dan item APRS mempunyai indeks kebolehpercayaan Cohen Kappa antara 0.75 hingga 0.87 , nilai kebolehpercayaan alpha cronbach dan kebolehpercayaan individu ialah 0.99 , dan nilai kebolehpercayaan item ialah 0.75. Analisis utama kajian ini menggunakan pendekatan kuantitatif yang disokong secara kualitatif melalui analisis dokumen serta temu bual pakar. APRS dibina memenuhi kriteria analisis komponen utama dan bersifat unidimensi. Hasil analisis mendapati konstruk APRS yang dominan ialah pengenalpastian, penilaian, pemilihan operasi dan pelaksanaan. Analisis DIF menunjukkan tidak terdapat perbezaan yang signifikan antara jurulatih dengan atlet, berdasarkan IPG. Analisis juga menunjukkan faktor kompetensi yang menyumbang terhadap APRS ialah pengetahuan dan kemahiran. Ini membuktikan bahawa pengetahuan dan kemahiran ialah faktor jurulatih kompeten terhadap APRS. Konstruk APRS yang dibina bersifat unidimensi dan disahkan 
memenuhi kriteria analisis komponen utama. Namun begitu, Jaffry Zakaria (2015) dan Fatimah Mustaffa (2015) juga tidak mengkaji pemboleh ubah mediator pengurusan risiko terhadap hubungan di antara perkhidmatan dengan kepuasan atlet bola tampar UA.

\section{Metod Kajian}

Kajian ini adalah bertujuan untuk mengenal pasti hubungan pengurusan risiko dengan kepuasan atlet dalam kalangan atlet di Universiti Awam Malaysia. Reka bentuk kajian kes dan berbentuk kuantitatif. Responden kajian adalah atlet daripada 20 buah Universiti Awam Malaysia. Responden kajian terdiri daripada kalangan atlet bola tampar lelaki dan wanita yang menjalani latihan dan bertanding bagi mewakili universiti bagi kejohanan antara universiti atau lain-lain kejohanan. Instrumen kajian adalah soal selidik yang diadaptasi kajian lepas mengenai pengurusan risiko dalam sukan dan kepuasan atlet. Soal selidik ini mengandungi tiga bahagian iaitu Bahagian A, Bahagian B dan Bahagian C. Bahagian A adalah maklumat demografi responden. Bahagian B pula soal selidik mengenai pengurusan risiko dan Bahagian $\mathrm{C}$ soal selidik mengenai kepuasan atlet.

Soal selidik Bahagian A ialah maklumat responden, penyelidik telah membina tiga item soalan iaitu jantina, kekerapan latihan dan peringkat tertinggi. Bagi soal selidik untuk bahagian B pula merangkumi 29 item bertujuan mengukur tujuh aspek dalam pengurusan risiko iaitu aspek tempat latihan, aspek pengetahuan jurulatih, aspek peralatan latihan, aspek aktiviti semasa latihan, aspek pengetahuan staf sukan, aspek aktiviti semasa latihan, dan aspek rekod kesihatan atlet. Bahagian C pula, penyelidik telah mengadaptasi 28 item merujuk kepada kepuasan atlet bagi mengukur tujuh aspek iaitu aspek pencapaian pasukan, aspek strategi pasukan, aspek latihan dan arahan, aspek integrasi pasukan, aspek kesungguhan pasukan, aspek etika pasukan dan aspek perbelanjaan pasukan. Bagi mengenal pasti hubungan antara pemboleh ubah pengurusan risiko dengan kepuasan atlet. Analisis ujian Korelasi Pearson Product Moment digunakan untuk menguji pada aras signifikan p<.05, dan perkaitan antara pemboleh ubah. Berdasarkan Hair et.al. (2015) penguji hipotesis-hipotesis ini digunakan bagi mengkaji sama ada terdapat hubungan antara pemboleh ubah tidak bersandar dengan pemboleh ubah bersandar. Ujian Korelasi Pearson juga digunakan untuk mengenal pasti kekuatan korelasi dan arah hubungan antara kedua-kedua pemboleh ubah seperti Jadual 1.

\section{Jadual 1: Skala Korelasi Pearson Poduct Moment}

\begin{tabular}{cc}
\hline Kekuatan Korelasi & Kekuatan Hubungan \\
\hline 0.90 hingga 0.99 & Sangat Kuat \\
\pm 0.70 hingga 0.89 & Kuat \\
\pm 0.40 hingga 0.69 & Sederhana Kuat \\
0 hingga \pm 0.39 & Lemah \\
\hline
\end{tabular}

Sumber: Hair et al. (2015)

\section{Hasil Kajian}

\section{Kekerapan latihan atlet}

Berdasarkan Jadual 2, jumlah keseluruhan responden dalam kajian ini adalah seramai 240 orang atlet.

Jadual 2: Perbezaan latihan berdasarkan kekerapan Latihan $(n=240)$

\begin{tabular}{ccc}
\hline Kekerapan latihan & Kekerapan & \% \\
\hline Seminggu Sekali Hingga Tiga Kali & 159 & $66.5 \%$ \\
Seminggu Empat Hingga Enam Kali & 60 & $25.0 \%$ \\
Setiap Hari & 21 & $8.5 \%$ \\
\hline
\end{tabular}


Merujuk kepada data kajian ini yang diperoleh, kekerapan latihan seminggu sekali hingga tiga kali adalah 159 kekerapan bersamaan (66.3\%), seminggu empat hingga enam kali adalah 60 kekerapan bersamaan (25\%) dan kekerapan latihan setiap hari adalah 20 kekerapan bersamaan $(8.3 \%)$.

\section{Peringkat tertinggi penglibatan atlet}

Berdasarkan Jadual 3, jumlah keseluruhan responden dalam kajian ini adalah seramai 240 orang atlet. Merujuk kepada data kajian ini yang diperoleh, bilangan atlet mengikut peringkat tertinggi adalah seperti berikut iaitu peringkat universiti adalah 129 bilangan $(53.7 \%)$, peringkat negeri adalah 76 bilangan (31\%), peringkat kebangsaan adalah 26 bilangan (10.8\%) dan peringkat antarabangsa adalah 9 bilangan $(3.8 \%)$.

Jadual 3: Perbezaan berdasarkan peringkat tertinggi $(n=240)$

\begin{tabular}{lll}
\hline Peringkat Tertinggi & Bilangan & \% \\
\hline Peringkat Universiti & 129 & $53.7 \%$ \\
Peringkat Negeri & 76 & $31.7 \%$ \\
Peringkat Kebangsaan & 26 & $10.8 \%$ \\
Peringkat Antarabangsa & 9 & $3.8 \%$ \\
\hline
\end{tabular}

\section{Hubungan pengurusan risiko dengan kepuasan atlet}

Merujuk kepada Jadual 4, menunjukkan kaedah korelasi Pearson Product Moment digunakan untuk mengkaji pengurusan risiko dengan kepuasan atlet. Dapatan kajian menunjukkan terdapat hubungan positif yang kuat $\mathrm{r}=.869$ antara pengurusan risiko dengan kepuasan atlet pada signifikan $\mathrm{p}<.01$. Hubungan ini bermaksud apabila pengurusan risiko adalah baik, maka kepuasan atlet juga adalah semakin tinggi.

Jadual 4 : Korelasi Pearson antara Pengurusan Risiko dengan Kepuasan Atlet (n=240)

\begin{tabular}{lll}
\hline & & Kepuasan Atlet \\
\hline Pengurusan Risiko & $r$ & $.869(*)$ \\
& $p$ & .000 \\
\hline
\end{tabular}

* Aras Signifikan:p<0.05

\section{Perbincangan Kajian}

Hasil kajian menyatakan terdapat hubungan antara pengurusan risiko dengan kepuasan atlet bola tampar di universiti. Jika dilihat dari sudut data yang diperolehi, pengurusan risiko adalah satu pemboleh ubah yang perlu dititik beratkan semasa menjalani latihan dan pertandingan. Pengurusan risiko adalah salah satu faktor yang meningkatkan kepuasan atlet dan sekaligus dapat mengekalkan dan membaiki prestasi atlet. Ini dapat dilihat berdasarkan dapatkan kajian yang menunjukan hubungan yang kuat terhadap kepuasan atlet. Dapatan menyatakan bahawa aspek-aspek dalam pengurusan risiko seperti tempat latihan, pengetahuan jurulatih, peralatan latihan, aktiviti semasa latihan, pengetahuan staf, aktiviti semasa pertandingan dan rekod kesihatan atlet memberi pengaruh kepada kepuasan atlet. Namun aspek aktiviti semasa pertandingan seperti penekanan terhadap pemanasan badan sebelum perlawanan, makluman kepada jurulatih jika terdapat kecederaan, penekanan aktiviti cooling down, tidak mengambil ubat terlarang dan mendapat rawatan jika terdapat kecederaan iaitu seperti membalut tempat yang cedera atau strapping anggota yang mengalami kecederaan.

Ini menyokong kajian Chunderpal dan Jhalukpreya (2010) dan Fatemeh et al., (2012) yang menyatakan aspek dalam pengurusan risiko seperti pengetahuan jurulatih serta penggunaan kemudahan dan peralatan adalah aspek yang penting dalam pengurusan risiko. Oleh yang demikian, 
pihak pengursan sukan dan jurulatih perlu mengambil berat terhadap aspek-aspek dalam pengurusan risiko bagi mengelak kecederaan berlaku terhadap atlet mereka semasa latihan dan pertandingan. Asha Hasnimy dan Mat Azmin (2011) serta Vince dan Emma (2014) menjelaskan berkaitan kecederaan anggota badan altet dalam latihan serta semasa pertandingan sering berlaku dan prosedur keselamatan boleh mencegah daripada kecederaan atlet. Oleh yang demikian, prosuder atau pengurusan risiko semasa latihan dan pertandingan amat perlu di praktikan dan ditekan oleh pihak yang terlibat seperti pengurusan sukan dan jurulatih.

Selain daripada itu, penyediaan pengurusan risiko semasa latihan dan pertandingan yang terdapat di universiti perlulah mementingkan atau memberi tekanan kepada aspek kepuasan, ini bagi meningkatkan prestasi latihan dan memberi keyakinan kepada atlet terhadap pengurusan sukan di universiti serta menghindar atlet daripada kemalangan dan kecederaan semasa latihan. Ini menyokong kajian yang telah dijalankan oleh Fagher et al., (2016) bahawa pengurusan kecederaan adalah penting bagi mencegah atau mengurangi kecederaan pada atlet. Beliau mengkaji persepsi atlet terhadap pengalaman kecederaan, faktor risiko dan pencegahan kecederaan. Hasil daripada dapatan kajian menunjukkan bahawa prosedur kesihatan, sukan dan keselamatan atlet perlu ada bersamaan program pencegahan. Selain daripada itu, Lachlan et al. (2014) dalam kajian terhadap atlet bola tampar yang mendapati risiko yang wujud dan sering berlaku dalam sukan bola tampar adalah seperti (i) pergelangan kaki terseliuh, (ii) bahu, (iii) patella (lutut), dan (iv) anterior ligamen cruciate. Oleh yang demikian, berdasrkan kajian Laclan James et al.,(2014), bertepatanlah dapatan kajian ini menyokong bahawa pengurusan risiko adalah hal yang penting dan ergonomik latihan dan pertandingan perlu di selenggara dengan baik serta dikawal selia oleh kakitangan yang berpengetahuan bagi mengelak kecederaan atau kemalangan berlaku semasa latihan dan pertandingan.

Selain itu, kajian ini menyokong kajian yang telah dijalankan oleh Nor et al. (2019), Anuar (2010), Asiah (2009) dan Muhamad Suhaimi dan Mohd Affendi (2021) yang menyatakan terdapat hubungan kepuasan berdasarkan kualiti ergonomik sukan. Berdasarkan hasil kajian ini, pihak pengurusan sukan di universiti perlulah merangka urus tadbir perkhidmatan agar persekitaran latihan berada dalam keadaan yang baik dan tidak bahaya. Aspek-aspek seperti tempat latihan, peralatan latihan, rekod kesihatan dan ilmu pengetahuan kakitangan sukan dan jurulatih perlu diberi penekanan bagi meningkatkan lagi tahap keselamatan dan kepuasan atlet dalam mencapai kecemerlangan sukan universiti. Dengan adanya urus tadbir yang baik terhadap pengursan risiko di semua univeristi atau kemudahan sukan, dapatlah mengurangkan kadar kecederaan atau kemalangan terhadap atlet yang tidak diingini oleh pengurusan sukan, jurulatih dan atlet khasnya.

\section{Kesimpulan}

Sebagai penutup, kajian menyimpulkan bahawa perkhidmatan sukan mempengaruhi kepuasan atlet di universiti dan ianya merupakan perkara penting dalam mewujudkan kestabilan dan keharmonian yang diperlukan oleh atlet dalam membina sebuah individu atau pasukan yang mempunyai kualiti dan prestasi yang tinggi bagi menjalani latihan dan mencapai kemenangan di sesebuah kejohanan. Dapatan kajian yang menunjukkan kekuatan hubungan perkhidmatan sukan dengan kepuasan atlet menerangkan bahawa semakin baik perkhidmatan sukan yang disediakan atau ditawarkan, maka semakin tinggi kepuasan atlet yang terhasil. Keadaan ini secara tidak langsung juga mempunyai hubung kait dengan aspek-aspek yang perlu ditekankan atau ditingkatkan dalam perkhidmatan yang mana ia membantu kakitangan sukan agar lebih kreatif dan inovatif dalam memberikan atau menyediakan perkhidmatan dalam sukan agar produk (kualiti atlet) yang dihasilkan akan memberi impak yang baik kepada universiti.

\section{Rujukan}

Anuar Din, Salleh Abd Rashid \& Mohd Isha Awang (2015). Aspek Pengurusan Program Latihan \& Kesannya Terhadap Kepuasan Atlet Sekolah Sukan. International Journal of Management Studies, 22(1), 73 - 95 
Aminuddin Yusof \& Shamsarizal Abd Aziz (2011). Hubungan Antara Kualiti Perkhidmatan Kemudahan Sukan Kolej Matrikulasi Dengan Kepuasan Pelajar. Universiti Putra Malaysia, Kajian yang tidak diterbitkan.

Asiah Hj Mohd Pilus, Aminuddin Yusof, Jamil Bojei, Mohd Sofian Omar Fauzee, Bahaman Abu Samah, Rabiatul Adawiah Ab Aziz (2010). The relationship of sportscape, motivation, loyalty satisfaction and intention to watch Malaysia Cup football. American Journal of Scientific Research, 7, 52-63

Berger, B. G. \& Tobar, D. A. (2007). Physical activity and quality of life: Key considerations.

In G. Tenenbaum \& R. C Eklund (Eds), Handbook of sport psychology (3rd ed., pp. 598-620). New York; Wiley \& Sons.

Collis, J. (2006). When Your Custamer Wins, You Can't Lose. New Delhi : Leads Press.

Chelladurai, P., \& Riemer, H.A. (1997). Aclassification of athlete satisfaction. Journal of Sport Managment, 11: 133-159.

Fatimah Mustaffa (2015). Konstruk amalan pengurusan risiko sukan kearah penghasilan kerangka konsep APRS jurulatih Institut Pendidikan Guru Malaysia. Tesis PhD. Fakulti Pendidikan Teknikal dan Vokasional Universiti Tun Hussein Onn Malaysia.

Haliyana Tonot \& Atiah Ibrahim (2014). Penilaian Kualiti Perkhidmatan Di One Stop Centre (OCS) Kolej Universiti Islam Antarabangsa Selangor (KUIS). Fakulti Pengurusan \& Muamalah (FPM).

Jaffry Zakaria, Mohd Taib Harun \& Norlena Salamudin (2015). Peranan amalan pengurusan risiko terhadap perkembangan aktiviti sukan dan rekreasi dalam meningkatkan kesejahteraan hidup masyarakat. ASEAN Comparative Education Research Network Conference 2015 7-8 Oktober 2015, Malaysia.

Lachlan P. James • Vincent G. Kelly • Emma M. Beckman (2014). Injury Risk Management Plan for Volleyball Athletes. Sports Med DOI 10.1007/s40279-014-0203-9.

Muhamad Suhaimi Taat \& Mohd Affendi Ariffin. (2021). Motivation as Mediator between the Qualities of Sports Services with the Development of Human Capital of Sports Culture: A Structural Equation Model Analysis. Turkish Journal of Computer and Mathematics Education, 12 (6), 3677-3681.

Nor Eeza Zainal Abidin*, Tajul Arifin Muhamad \& Jamil Ahmad (2019). Kualiti Perkhidmatan Fasiliti Sukan di Universiti Awam Malaysia. Jurnal Pendidikan Malaysia, 44(1) Isu Khas, 55-66.

Riemer, H.A., \& Chelladurai, P (1998). Development of the athlete satisfaction questionnaire (ASQ). Journal of Sport exercise psychology, 20, 127-156.

Jin Ho Choi. (2006). The relationship among tranformational leadership, organizational outcomes, and service quality in five major NCAA conferences. Master Thesis, Texas A\&M University, USA Texas. 